\author{
1990 \\ Nematologica 36 (1990): 205-216, E. J. Brill, Leiden
}

$\therefore$

\title{
RATIOS AND INDEXES IN NEMATODE TAXONOMY
}

\author{
BY
}

\section{R. FORTUNER}

California Department of Food and Agriculture, Analysis \& Identification, P.O. Box 942871 , Sacramento, CA 94271-0001, U.S.A.

It is proposed to call "Index" the ratios traditionally included in nematode descriptions (ratios $a, b, c, V$, etc.) when they are used as a numerical expression of an ordered qualitative character (such as the shape or the position of an organ), and to reserve the name of "Ratios" to the entities recently reviewed by Roggen, Revets and Van den Berghe (Nematologica, 1987). It is shown that it is always possible to use an index instead of an ordered qualitative character for describing a shape or a position, as long as the index is biologically related to the characteristic being described. Indexes are more objective than the corresponding qualitative characters. Also, they can be used in parametric statistical analyses, and in particular in discriminant function analyses.

Keywords: qualitative characters, shapes, morphology, statistical analyses, discriminant analysis, nematode descriptions, taxonomy.

It has often been said that the ratios $\alpha, \beta$ and $\gamma$ of de $\operatorname{Man}(1880)$, and many similar ratios that have been proposed since then in nematode taxonomy, have severe limitations and that their use is often unjustified according to strict statistical procedures (Roggen \& Asselberg, 1971; Fortuner, 1984). Recently, Roggen et al. (1987) reviewed the use of ratios and they proposed new procedures to test their validity. Their analysis is quite correct, but they considered only one of the possible uses of ratios. They assumed that ratios are supposed to be "independent of the size of the object the ratio describes"; that when we use a ratio or index, "a gain of information is expected"; that this gain can be measured simply by the reduction of the variability; and that "a ratio will be most useful when it is unbiased and as constant as possible".

Roggen et al. (1987) did not consider another possible use of ratios, that of indicators of shape or position. To distinguish clearly between the two uses, I propose to reserve the term 'ratio' for the mathematical entities discussed by Roggen et al. (1987), and to call 'index, indexes' (or indices) the numerical expression of the shape or the position of an organ. These two words differ in their etymology, one from the Latin ratio, computation, and the other from indicare, to indicate.

Shapes in nematodes are often described with words, e.g. lip region high, stylet short, stylet knobs robust, vulva prominent, tail elongate, etc. as opposed to numerical expressions (real numbers, integers). Qualitative charac- 
ters can be ordered (character ordinal, discrete, e.g. size of stylet: very smallsmall-intermediate-large-very large) or unordered (character nominal, discrete, e.g. posterior edge of body annuli: plain-crenated-with fringes-with scales; or nominal, binary, e.g. type of oviduct: disc-tube).

Of the 348 characters listed in Fortuner (1989), 173 are qualitative (twostate or multi-states, ordered or not ordered) characters, 101 are measurements, and 23 are ratios. This list is being revised and more qualitative characters than measurements are being discovered. Nany qualitative characters used in plant-parasitic nematodes are ordinal, discrete characters.

There is a certain lack of objectivity in the use of qualitative characters. What seems high to one observer may seem intermediate to another. The attribution of character states depends heavily on the observer, not only on his experience but also on his domain of expertise. To one used to work with hoplolaimid nematodes, a $20 \mu \mathrm{m}$ long stylet will appear to be short, but it will look quite large to a specialist in anguinids. Whitehead (1959) described the body of Hoplolaimus abcrans (now Scutcllonema abcrrans) as "stout" and with ratio a (body length/body maximum diameter) equal to 23.5 . The term stout is traditionally used for members of Criconematinae (see for example the diagnosis of this subfamily in Raski \& Luc, 1987) with ratio a of about 10 to 15.

It can be argued that there are more risks of error in the textual description of a character. For example, Das \& Sultana (1979) described the lip region of Pratylenchus barkati as "about $1 / 2$ as wide as high" whereas they obviously meant the opposite (the low lip region of this species is $1 / 2$ as high at it is wide).

The various states of qualitative character are difficult to compare to each other. If a species $A$ is said to have lip region high, and species $B$ to have lip region very high, it is not certain that the two species are really different. The only way to make sure of the difference would be to compare figures or actual specimens of both species, but then the original character would no longer be used. Qualitative characters do not lend themselves to mathematical treatment. What is the relation between a high and a low lip region? Is it twice as high? Three times as high? The difference between an ordinal character and a measurement is that it can only be said that the value $x A$ of an ordinal character in species $A$ is smaller than, equal to, or greater than $x B$ in species $B$, while if a measurement $x A$ is greater than $x B$, it can be said that i) $x A$ is $x A / x B$ greater than $x B$, or ii) $x A$ is $x A-x B$ units greater than $x B$.

Expressing ordinal characters numerically would solve these problems, at least partly. There are different ways to effect this transformation, depending on the type of characters.

Some qualitative characters can easily be arranged in an ordered series. For example, lip region can be described as $1=$ very low, $2=$ low, $3=$ moderately low, $4=$ intermediate, $5=$ moderately high, $6=$ high, and $7=$ very high. Grading each specimen would still include a measure of subjectivity, that could be reduced by using standardized illustrations. A proper choice of the grades, 
and their corresponding shapes, would allow some mathematical treatment if a high lip region (high $=6$ ) really is 3 times as high as a low one (low $=2$ ).

Other qualitative characters are textual expressions of size, and they can be replaced by a measurement or a count. For example, the character 'stylet, short' can be replaced by the measure in micrometers of the overall length of this organ. The character 'tail annuli, abundant' can be replaced by the number of tail annuli.

Such transformations are well known and in common usage. In the present paper, I argue that the ratios (under the name of indexes as defined above) between two dimensions of an organ also can be used to quantify a particular aspect of the shape of this organ. A list of indexes, either already in use as ratios or new indexes, is presented in Table I, together with the qualitative characters they profess to replace. Shapes are not independent of size (for example, a filiform tail is always a long tail), and indexes are not expected to have low or null correlation with size related variables (index $c^{\prime}$ will be higher in forms with longer tails). Using indexes instead of the corresponding qualitative character is not expected to result in a gain of information in the sense argued by other authors as explained above, but rather to offer a different kind of information about phenomena traditionally described by words.

TABLE I

Some examples of qualitative, ordinal characters that are, or can be expressed as indexes

\begin{tabular}{|c|c|c|}
\hline Ordinal character & Index & Definition \\
\hline Body relative thickness & Index a & Body length / diameter \\
\hline Tail relative length & Index $c^{\prime}$ & Tail length / diameter at anus \\
\hline Lateral field relative width & & Lateral field width / body diameter \\
\hline Labial region elevation & & Labial region height / width \\
\hline $\begin{array}{l}\text { Postion of phasmid relative } \\
\text { to anus }\end{array}$ & & $\begin{array}{l}\text { Number of annuli tail end - phasmid / } \\
\text { number of tail annuli }\end{array}$ \\
\hline $\begin{array}{l}\text { Position of hemizonid relative to } \\
\text { excretory pore }\end{array}$ & & $\begin{array}{l}\text { Distance anterior end - hemizonid / } \\
\text { distance ant. end / ex. pore }\end{array}$ \\
\hline Position of scutella on body & & $\begin{array}{l}\text { Distance anterior end - scutellum / } \\
\text { body length \% }\end{array}$ \\
\hline Size of glandular overlap & & $\begin{array}{l}\text { Overlap length / distance median bulb to } \\
\text { end of glands } \%\end{array}$ \\
\hline Position of.DGO in procorpus & & $\begin{array}{l}\text { Distance median bulb valve - DGO / } \\
\text { Distance bulb valve - knobs } \%\end{array}$ \\
\hline $\begin{array}{l}\text { Position gland nuclei relative to } \\
\text { oesophago-intestinal valve }\end{array}$ & & $\begin{array}{l}\text { Distance median bulb valve - nucleus / } \\
\text { Distance bulb valve - oes. int. valve }\end{array}$ \\
\hline Stylet cone relative size & Index m & Cone length / stylet length \% \\
\hline $\begin{array}{l}\text { Position of median bulb in } \\
\text { oesophagus }\end{array}$ & Index $\mathrm{MB}$ & $\begin{array}{l}\text { Length of oesophagus / distance ant. end } \\
\text { to median bulb valve }\end{array}$ \\
\hline Shape of median bulb & & Bulb length / width \\
\hline Position of vulva on body & Index $V$ & $\begin{array}{l}\text { Distance anterior end - vulva / body } \\
\text { length \% }\end{array}$ \\
\hline $\begin{array}{l}\text { Regression posterior genital } \\
\text { branch }\end{array}$ & & $\begin{array}{l}\text { Length of posterior branch / length } \\
\text { anterior branch \% }\end{array}$ \\
\hline
\end{tabular}


It is true that an index having all the characteristics of a ratio will be subject to the same limitations. However, by changing the purported use of indexes, we now find that these limitations no longer matter, because they do not prevent the new use proposed for indexes. Finally, it must be understood that, although indexes are proposed as a replacement for qualitative characters, they are not qualitative characters themselves, and they are not subject to the same limitations as qualitative characters. To illustrate this last point, an analogy may be traced with the replacement of an ordinal character such as 'stylet, size' described as short, intermediate or long by the measurement 'stylet, length' measured in micrometers. Mean and standard deviation cannot be calculated for 'stylet, size', but nobody will dispute that they can be easily obtained from a straight measurement. Similarly, these statistical parameters cannot be calculated for an ordinal character such as 'tail, shape' from elongate to stubby, but mean and standard deviation can be associated to an index $c^{\prime}$ (tail length/tail diameter) that describes the same phenomenon.

Various questions that can be raised about the validity of using indexes are addressed below.

\section{General accuracy}

An index is more objective than the corresponding qualitative character. Once an index is defined, its value in a specimen does not depend on the personal interpretation of the observer. Nematode taxonomists may disagree on what is a high or a low lip region, but they all agree on the definition of indexes $\mathrm{a}, \mathrm{b}, \mathrm{c}, \mathrm{V}$, etc.

There are less risks of error in the computation of an index than in choosing one of the possible states of a qualitative character. Errors may be made in the measurement of the constituent distances, or in the computation itself, but the mistake of Das \& Sultana (1979) in the description of Pratylenchus barkati reported above probably would not have occurred had they used an index defined as the quotient of lip height by lip width.

Indexes are more precise than qualitative characters. Index $\mathrm{V}$ (distance anterior end to vulva as a percentage of body length) gives an exact estimate of the position of the vulva along the body, while the corresponding character "Vulva at mid-body"' may be used for specimens with, e.g., V $=55 \%$ as well as for other specimens with, e.g. $V=45 \%$. Relative size of anterior end is usually given as "high" or "low", but the anterior end of a Hirschmanniella will appear to be low for someone more familiar with e.g. Hoplolaimids, whereas it will be seen as high when compared to the anterior end of a Pratylenchus. An index computed as "body diameter at base of anterior end/height of the anterior end" will give an exact and more objective measure of the relative elevation of the anterior region. It is interesting to compare the traditional description of the elevation of the lip region (always given as low in Pratylen- 
chidae, high in Hoplolaimidae, etc.) to the values of such an index. Typical Pratylenchus species have an index of 0.25 to 0.35 , Scutellonema bradys in Hoplolaimidae has an index of 0.60 , but Radopholus similis (0.40) in Pratylenchidae is very close to Helicotylenchus multicinctus (0.45) in Hoplolaimidae.

\section{Statistical validity}

For discussions on the statistical validity of indexes it is easier to consider separately the computation of an index in a single specimen, and the computation of the statistical parameters (mean, standard deviation, etc.) of the same index measured in several specimens of a sample.

2.1. Computation of an index in one specimen. There is no mathematical or statistical restriction whatsoever to dividing the distance measure of a organ in a specimen by the distance measure of another organ in the same specimen as long as they both use the same unit, and that the divisor is not null. For example, it is always possible, mathematically speaking, to divide e.g. the body diameter at the base of the cephalic region by the height of this region.

The only question is biological: is the index a good descriptor of the character it pretends to replace. This biological question needs to be answered for every index a taxonomist wants to use. If one makes $\mathrm{N}$ measurements on a nematode, there are $\mathrm{N}(\mathrm{N}-1) / 2$ pairs of these measurements that are candidates for being proposed as indexes, and the nematologist must carefully choose those that truly represent the shapes he or she wants to describe. For example, the character "relative shape of the cephalic region: low/high" is well represented by the index "body diameter at the base of the cephalic region/height of this region" because of the meaning of the character states "low" (having a small upward extension or elevation) and "high" (having large extension upward). Actually, a textual expression such as "Lip region about $1 / 2$ as high as wide" looks very similar to an index computed as height of lips/width of lips $=0.5$. Extension or elevation is understood as the measure of the elevation of the cephalic region above the line formed by the base of the cephalic region. The value of this elevation, or height of the cephalic region, is made dimensionless by being divided by the diameter at the base of the cephalic region. The index proposed is thus a direct expression of the shape described by the corresponding qualitative character. Some authors may argue against its biological meaning, for example by pointing out that there is some uncertainty in the actual position of the base of the cephalic region in specimens where this region is not distinctly set-off from the rest of the body outline. However, in this case the qualitative character also is doubtful, and the validity of the index itself is not in question.

It is conceivable that more and more indexes can be used, at the discretion of nematologists, to describe new relationships within or between organs. For 
example, an index can be proposed "length of posterior genital branch/length of anterior branch" to express the amount of degeneration of the posterior genital branch in some nematode species. Another index "distance tail end to right phasmid/distance tail end to left phasmid" could be used to express the fact that in some species the right and left phasmids are not opposite to each other. The use of indexes is limited only by the imagination of nematologists.

2.2. Computation of the statistical parameters of an index in a population sample. Here, it is important to remember the distinction made above between indexes and the corresponding ratios.

Ratios are mathematical functions between two distances, and their use is governed by several mathematical and statistical considerations, excellently reviewed by Roggen $e t$ al. (1987).

Indexes are indications of shapes or positions, and they exist independently of the distances that were used to compute them. Index $a$ is computed in an individual specimen by dividing its body length by its body diameter. Index $a$ is here considered as an expression of the general shape of the body of individual specimens. not as part of the function body length $=f$ (body diameter) for the population. While the ratios discussed by Roggen t al. (1987) are expected to be constant, various endogenous and exogenous factors induce a certain variability of the general shape of the body, with some specimens a little fatter than average, others a little thinner. This is reflected by the variation of index $a$ from one specimen to the next. One cannot expect an index such as index $a$ to be constant considering the variation in the qualitative character it pretends to replace, with nematode bodies of variable relative thickness. The only time an index is constant is when the corresponding qualitative character itself is constant. An index does not need to be less variable than the measurements used to compute it, because its usefulness is not measured by a reduction of variability, but by the increase in objectivity it gives from the corresponding qualitative character.

This is not to say that the distribution of an index is expected to be quite normal. In fact, it cannot be normal if that of the index constituents are normally distributed, and conversely. In real life, no variable has a perfectly normal distribution. Table II shows the coefficients of skewness and kurtosis and the result of a test of normality for some raw data and the corresponding indexes from the type population of Hirschmanniella belli, as recently remeasured (Fortuner \& Maggenti, 1990). The small values of $W$ in Table II lead to the rejection of the null hypothesis, that the sample is normally distributed. One can see that, as a rule, indexes are less normal than their constituent measurements. However, the distribution of some indexes is close to normal. For example, index $a$ has a skewness of only 0.19 , and a $W$ of 0.53 . The index coefficient of reduction of the posterior genital branch, as compared to the length of the posterior genital branch is actually closer to normal than one of 
its constituents (length of the posterior branch). Also, some straight measurements taken from the same sample of $H$. belli are far from normal, as for example the distance from head to nerve ring given in Table II for comparison. Indexes are not always normally distributed, but neither are all raw variables. Concerns for normality in some analyses should be addressed, but each case should be studied for itself, in the particular circumstances of each study and of each variable. There is no reason to reject all indexes outright because they do not conform to a normal distribution.

\section{TABLE II}

Distribution of some measurements and of the indexes computed from these measurements in the type population of Hirschmanniella belli remeasured in Fortuner \& Maggenti (1990)

\begin{tabular}{lrrccll}
\hline Characters & Mean & Std. Dev. & Skewness & Kurtosis & W:normal & Prob $<W$ \\
\hline Body length & 1728.29 & 128.96 & -0.19491 & -0.15156 & 0.992056 & 0.9988 \\
Diameter & 24.27 & 2.40 & 0.04075 & -0.49238 & 0.991156 & 0.9979 \\
Ratio a & 71.70 & 7.34 & 0.199291 & -0.8110 & 0.956462 & 0.5311 \\
Oesophagus & 140.76 & 12.85 & -0.63741 & 1.685594 & 0.948691 & 0.4065 \\
Ratio B & 12.37 & 1.47 & 1.497672 & 2.831437 & 0.873825 & 0.0196 \\
Gland length & 327.03 & 33.56 & -1.25533 & 2.329694 & 0.915546 & 0.1101 \\
Ratio b' & 5.35 & 0.79 & 1.58298 & 3.541487 & 0.860819 & 0.0115 \\
Tail length & 106.56 & 9.16 & -0.375 & -0.68775 & 0.963346 & 0.6560 \\
Ratio c & 16.29 & 1.37 & 1.100818 & 2.48548 & 0.92181 & 0.1424 \\
Anal diameter & 19.77 & 3.21 & 0.63255 & -0.83017 & 0.909803 & 0.0868 \\
Ratio c' & 5.49 & 0.73 & -1.14959 & 0.8945 & 0.895992 & 0.0489 \\
Head-vulva dist. & 896.29 & 62.85 & 0.40716 & 0.497286 & 0.966336 & 0.7121 \\
Ratio V & 51.90 & 1.34 & 0.402498 & -0.84172 & 0.944098 & 0.3435 \\
Stylet length & 19.23 & 0.70 & -0.35938 & 0.500648 & 0.960292 & 0.5994 \\
Stylet cone & 9.13 & 0.46 & 0.02976 & -0.85149 & 0.970172 & 0.7827 \\
Ratio M & 47.50 & 1.65 & -0.13852 & 0.164618 & 0.937321 & 0.2651 \\
Ant. genital branch & 344.37 & 51.91 & -0.00876 & -0.8892 & 0.96582 & 0.7024 \\
Post. genital branch & 341.56 & 60.18 & 0.947195 & 0.90129 & 0.93821 & 0.2745 \\
Reduction post branch & 99.20 & 7.99 & 0.548337 & 2.21308 & 0.943027 & 0.3299 \\
Head-nerve ring & 113.75 & 7.41 & 1.033162 & 1.838959 & 0.907069 & 0.0775 \\
\hline
\end{tabular}

\section{Use of Indexes in Discriminant Function Analyses}

Discriminant function analysis (DFA) is a very powerful tool for the characterization of the distance that may or may not exist between two or several groups of specimens. For this reason, DFA are particularly well suited for species discrimination. However, their usefulness is often limited for taxonomists by the fact that only quantitative characters can be included in a DFA. It has often been said that shapes were a better indication of specific differences than measurements, because shapes-were less influenced by external 
factors. Using indexes as measures of shapes allows both types of character to be included in a DFA.

Using DFA requires that the discriminating variables follow some basic assumptions (Klecka, 1980), and we must now examine these assumptions to check whether any would be violated by the use of indexes.

3.1. Variables measured at the interial or ratio level of measurement. Discriminating variables used in a DFA must be measured at the interval or ratio level of measurement (ratio is here taken in its mathematical sense, not in the sense of taxonomic ratio). Their means and variances can be calculated and they can be legitimately employed in mathematical expressions. This is verified for indexes that are measured at the ratio level of measurement. Indexes are dimensionless numbers, but that does not prevent their use in mathematical expressions.

3.2. Linear combination of iariables. No variable may be a linear combination of other discriminating variables. Indexes are not sums and they do not fall within this interdict. This condition alone would not prevent the simultaneous use of length $\mathrm{L}$, diameter $\mathrm{D}$ and index $\mathrm{a}(\mathrm{a}=\mathrm{L} / \mathrm{D})$ in $\mathrm{a} D F A$.

3.3. Correlation between variables. Two variables that are perfectly correlated cannot be used at the same time. Using indexes in a DFA will cause problems when the index is highly correlated with at least one of its constituents, if this constituent is also part of the DFA.

It must be said here that no variable, be it straight measurement, integer, or ratio, is perfectly uncorrelated with any other variable. The raw variables always have some degree of correlation with each other, from low to high to highly significant. Table III shows the correlation coefficients of selected pairs of variables between themselves and with the index they form in the same sample as used in Table II. It can be seen that indexes $a, b$, and $b^{\prime}$ are more highly correlated with both their constituent variables than these variables are from each other. On the other hand indexes $c$ and $c^{\prime}$ are less correlated with one of their two constituent variables than the two variables with each other. Finally, indexes $\mathrm{m}, \mathrm{V}$, and the coefficient of reduction of the posterior genital branch have a lower correlation with their constituents than the constituents with each other. To place these results in perspective, it should be said that in the sample of $H$. belli in Table II (Fortuner \& Maggenti, 1990), the straight measurement body length is very highly correlated ( $P$ less than 0.0001 ) with two, and significantly correlated (P less than 0.05 ) with six, of the 22 other straight measurements taken in the sample.

The indexes advocated here will have some degree of correlation with the other variables, but there will be some correlation between these other variables also. Highly correlated variables must not be used simultaneously in 
Correlations between some variables and the indexes they form in the type population of "Hirschmanniella belli remeasured in Fortuner \& Maggenti (1990)

\begin{tabular}{|c|c|c|c|}
\hline $\begin{array}{l}\text { Variables } \\
1\end{array}$ & 2 & Correlation & $\begin{array}{l}\text { Test: } \\
\mathrm{P} \text { level }\end{array}$ \\
\hline $\begin{array}{l}\text { Body length } \\
\text { Body length } \\
\text { Body diameter }\end{array}$ & $\begin{array}{l}\text { Body diameter } \\
\text { Index a } \\
\text { Index a }\end{array}$ & $\begin{array}{r}0.31946 \\
0.41767 \\
-0.72210\end{array}$ & $\begin{array}{l}0.1963 \\
0.0846 \\
0.0007\end{array}$ \\
\hline $\begin{array}{l}\text { Body length } \\
\text { Body length } \\
\text { Oesophagus }\end{array}$ & $\begin{array}{l}\text { Oesophagus } \\
\text { Index } b \\
\text { Index } b\end{array}$ & $\begin{array}{r}0.20409 \\
0.49956 \\
-0.73887\end{array}$ & $\begin{array}{l}0.4166 \\
0.0348 \\
0.0005\end{array}$ \\
\hline $\begin{array}{l}\text { Body length } \\
\text { Body length } \\
\text { Oesophagus + overlap }\end{array}$ & $\begin{array}{l}\text { Oesophagus + overlap } \\
\text { Index } b^{\prime} \\
\text { Index } b^{\prime}\end{array}$ & $\begin{array}{r}-0.04063 \\
0.55098 \\
-0.84225\end{array}$ & $\begin{array}{l}0.8728 \\
0.0178 \\
0.0001\end{array}$ \\
\hline $\begin{array}{l}\text { Body length } \\
\text { Body length } \\
\text { Tail length }\end{array}$ & $\begin{array}{l}\text { Tail length } \\
\text { Index } c \\
\text { Index } c\end{array}$ & $\begin{array}{r}0.49254 \\
0.39072 \\
-0.60253\end{array}$ & $\begin{array}{l}0.0378 \\
0.1089 \\
0.0081\end{array}$ \\
\hline $\begin{array}{l}\text { Tail length } \\
\text { Tail length } \\
\text { Tail diameter }\end{array}$ & $\begin{array}{l}\text { Tail diameter } \\
\text { Index } c^{\prime} \\
\text { Index } c^{\prime}\end{array}$ & $\begin{array}{r}0.40611 \\
0.09791 \\
-0.86434\end{array}$ & $\begin{array}{l}0.0945 \\
0.6991 \\
0.0001\end{array}$ \\
\hline $\begin{array}{l}\text { Body length } \\
\text { Body length } \\
\text { Discance to vulva }\end{array}$ & $\begin{array}{l}\text { Distance to vulva } \\
\text { Index } \mathrm{V} \\
\text { Index } \mathrm{V}\end{array}$ & $\begin{array}{r}0.93950 \\
-0.37644 \\
-0.03733\end{array}$ & $\begin{array}{l}0.0001 \\
0.1236 \\
0.8831\end{array}$ \\
\hline $\begin{array}{l}\text { Stylet length } \\
\text { Stylet length } \\
\text { Cone length }\end{array}$ & $\begin{array}{l}\text { Cone length } \\
\text { Index } \mathrm{m} \\
\text { Index } \mathrm{m}\end{array}$ & $\begin{array}{r}0.71937 \\
-0.01359 \\
0.68465\end{array}$ & $\begin{array}{l}0.0008 \\
0.9573 \\
0.0017\end{array}$ \\
\hline $\begin{array}{l}\text { Anterior genital branch } \\
\text { Anterior genital branch } \\
\text { Posterior genital branch }\end{array}$ & $\begin{array}{l}\text { Posterior genital branch } \\
\text { Reduction posterior } \\
\text { Reduction posterior }\end{array}$ & $\begin{array}{r}0.86832 \\
-0.01849 \\
0.47622\end{array}$ & $\begin{array}{l}0.0001 \\
0.9419 \\
0.0457\end{array}$ \\
\hline
\end{tabular}

a DFA, but it does not necessarily follow that it is the index that must be eliminated. Another option is to reject the two original measurments and to keep only their index. This decision should be taken from purely biological considerations as opposed to statistical considerations. During the comparison of the sample of $H$. belli used in Tables II and III with other samples (Fortuner \& Maggenti, 1990), seven variables were selected for the final DFA, including two indexes. The corresponding measurements constituting these indexes were not included.

3.4. Equality of the covariance matrices. Population covariance matrices must be equal for each group. This must be tested for indexes in the same way as it is tested for straight measurements. For example, in the statistical package SAS PC, the classification criterion is based on either the individual withingroup covariance matrices or the pooled covariance matrix, depending on a likelihood ratio test of the homogeneity of the within-group covariance 
matrices (SAS/STAT Guide). Using indexes will or will not affect the results of this test, in the same way that using any measurement will or will not affect it, depending on the effect that the addition of this index or measurement will have on the equality of the population covariance matrices of the various groups. In this sense, using an index does not place any more restrictions on the DFA than using any other type of quantitative variable.

3.5 Normal distribution. There must be a multivariate normal distribution in each group. This is almost in direct opposition to the concept of ratios as studied by Roggen $t$ t al. (1987). For these authors, "a ratio will be representative of a population when it is nearly constant". Here we see that in order to be used in a DFA, an index must follow a normal distribution, a condition certainly not met if the index remains constant. "Good" ratios, such as ratio $V$ that is often nearly constant in many nematode populations and species must be carefully checked before they are used as indexes in a DFA. If index $V$, or any other index, happens to be perfectly constant in one of the groups in a DFA, the variable becomes non-parametric and the strict application of the statistical assumptions would eliminate it from the analysis.

As we have seen above, and from the data in Table II, indexes are often far from being normally distributed, but so are many straight variables. Actually, DFA are quite robust and they may perform satisfactorily even though one or a few of the variables do not quite follow the assumption of a normal distribution. It may be necessary to discard some of the variables. indexes or straight measurements. because their distribution deviates too far from the normal distribution, but this is a decision to be considered case by case and variable by variable, and there is no justification for a blanket rejection of all indexes. The distribution of indexes is often somewhat skewed, but so are the distributions of the raw data. Deciding which to use of the raw measurements or their ratios, is a decision to be taken by the nematologist.

\section{DISCUSSION}

Indexes are very useful, and their validity cannor be measured by the criteria suggested for ratios by Roggen $\epsilon t$ al. (1987).

Indexes are more objective, more precise, and less error prone than qualitative characters for describing shapes or positions of organs. It has been shown that they can be used in DFA. One can argue that it is not necessary to use indexes at all because any information about shape that may be contained in the original measurements will affect the loading factors of the measurement variables in the second discriminant function defined by the analysis (function mostly related to shape whereas the first function is mostly related to size). However, while the fine analysis of the discriminant functions would be preferred by a statistician, a taxonomist will be more at ease interpreting actual shape indexes. 
There are other methods than DFA for demonstrating the relationships between groups of specimens and there are other ways to replace a qualitative character by a real number. For example, shape of the anterior face of stylet knobs (outline of the organ seen in lateral view), traditionally given as a qualitative character (anterior face indented, flattened, rounded, sloping backward) can be measured by the angle between the stylet axis and a tangent to the anterior face. The shape of the cephalic region outline in lateral view (rounded, flattened) can be measured by estimating the amount by which the cephalic region outline varies from a half-circle (shape factor $=2 / R^{*}$ Area/Perimeter; the shape factor for a half-circle is 1 ). A complex shape can be measured by a Fourier transform or other similar transforms.

Indexes are preferred here and in common taxonomic usage because they have been in constant use in nematology for the last hundred years, and because they are easy to compute. They have limitations, but no more than straight measurements. Whether to use indexes is a decision that every taxonomist must take, after considering the data, but there are no statistical arguments for rejecting them outright.

\section{RÉSUMÉ \\ Index et rapports}

Il est proposé d'appeler "index" les rapports traditionnellement inclus dans les descriptions de nématodes (rapports $a, b, c, V$, etc.) lorsqu'ils sont utilisés comme l'expression numérique de la forme ou de la position d'un organe, et de restreindre le nom de "rapports" aux concepts récemments discutés par Roggen, Revets et Van den Berge (Nematologica, 1987). Il est montré qu'il est toujours possible d'employer un index au lieu d'un caractère qualitatif pour décrire une forme ou une position, à condition que biologiquement, l'index soit bien en rapport avec la caractéristique qu'il prétend décrire. Les index sont plus objectifs que les caractères nominaux correspondants. De plus, ils peuvent être soumis aux analyses statistiques paramétriques, en particulier aux analyses de fonctions discriminantes.

\section{REFERENCES}

Das, V. M. \& Sultana, S. (1979). Five new species of the genus Pratylenchus from vegetable crops of Hyderabad (Andhra Pradesh). Indian Journal of Nematology 9, 5-14.

De Man, J. G. (1880). Die Einheimischen, frei in der reinen Erde und im süssen Wasser lebende Nematoden. Vorläufiger Bericht und descriptivsystematischer Theil. Tijdschrift van de Nederlandse Dierkundige Vereeniging 5, 1-104.

Fortuner, R. (1984). Morphometrical variability in Helicolylenchus Steiner, 1945. 5: On the validity of ratios. Revue de Nématologie 7, 137-146.

Fortuner, R. (1989). Nematode identification and expert system technology. New York and London, Plenum Press, ix +386 pp.

Fortuner, R. \& MAGGENTI, A. R. (1990). A statistical approach to the objective differentiation of Hirschmanniella oryzae from $H$. belli (Nemata: Pratylenchidae). Accepted in: Revue de Nématologie

Klecka, W. R. (1980). Discriminant Analysis. Beverly Hill, London, Sage Publications, Series: Quantitative Applications in the Social Sciences, $\mathrm{n}^{\circ} 19,71 \mathrm{pp}$.

RASKI, D. J. \& Luc, M. (1987). A reappraisal of Tylenchina (Nemata). 10. The superfamily Criconematoidea Taylor, 1936. Revue de Nématologie 10, 409-444. 
Roggen, D. R. \& Asselberc, R. (1971). The use of ratios in nematology. Nematologica 17, 187-189.

Rogcen, D. R., Revets, S. \& VAN DeN Berghe, W. (1987). Using ratios. Nematologica 32 (1986), 398-407.

SAS Institute Inc., SAS/STAT Guide for Personal Compulers, Version 6 Edition. Gary, NC, SAS Institute Inc., 1985, Chapter 9. The DISCRIM Procedure: 83-110.

Whitehead, A. G. (1959). Hoplolaimus abertans n. sp. (Hoplolaiminae: Tylenchida). Nematologica $4,268-271$. 